18

\title{
Полевой эффект при формировании интерфейса однослойного графена с водой
}

\author{
(ㄱ А.В. Бутко ${ }^{1}$, В.Ю. Бутко ${ }^{1,2,}$, С.П. Лебедев ${ }^{3}$, А.А. Лебедев ${ }^{1}$, Ю.А. Кумзеров ${ }^{1}$ \\ ${ }^{1}$ Физико-технический институт им. А.Ф. Иофрфе РАН, \\ Санкт-Петербург, Россия \\ ${ }^{2}$ Санкт-Петербургский академический университет, \\ Санкт-Петербург, Россия \\ ${ }^{3}$ Санкт-Петербургский национальный исследовательский университет \\ информационных технологий, механики и оптики, \\ Санкт-Петербург, Россия \\ ฯ E-mail: vladimirybutko@gmail.com
}

(Поступила в Редакцию 25 мая 2018 г.)

\begin{abstract}
Для создания ряда новых электронных устройств на основе графена, включая химические и биологические сенсоры, важное значение имеет установление закономерностей влияния интерфейса на электрические свойства графена. В данной работе созданы и исследованы структуры для транзисторных и четырех контактных электрических измерений на основе однослойного графена, выращенного путем термического разложения карбида кремния в атмосфере аргона. Изучалось влияние на электрические свойства графена добавления воды на его поверхность и обратного процесса ее высушивания. Установлено, что в исследуемых структурах полевой эффект является основным механизмом влияния формирования интерфейса графена с водой на его электрические свойства.

Часть финансирования для проведения исследований предоставлена Физико-техническим институтом им. А.Ф. Иоффе, Санкт-Петербургским академическим университетом и Комитетом по науке и высшей школе правительства Санкт-Петербурга.
\end{abstract}

DOI: 10.21883/FTT.2018.12.46742.148

\section{1. Введение}

Графен перспективен для создания ряда электронных устройств, включая химические и биологические сенсоры. Поэтому особый интерес в последнее время вызывают интерфейсные эффекты, влияющие на электрические свойства графена [1-8]. В том числе, большое внимание направлено на создание и изучение сенсорных устройств, в которых исследуемые водные растворы находятся в интерфейсном контакте с графеном [1-6,9-12]. Интерфейсный эффект в структурах на основе выращенного в условиях вакуума четырехслойного графена, демонстрирующего дырочный тип проводимости, исследовался нами в работе [5] путем четырех контактных электрических измерений. В указанной работе наблюдался рост сопротивления этого типа графена примерно на $25 \%$ в области его интерфейса с водой. Механизм данного интерфейсного эффекта не вполне понятен. Возможно, за этот эффект ответственен механизм, предложенный в работе [13], при котором повышение сопротивления графена обусловлено снижением подвижности носителей заряда под действием разупорядоченных кулоновских центров на интерфейсе графена с жидкостью. В последующей работе нам удалось осуществить и оптимизировать выращивание высококачественного графена, путем термического разложения карбида кремния в атмосфере аргона. Диагностика качества и оценка толщины таких образцов графена была выполнена в работе [6]. В результате диагностики было установлено, что $\sim 85 \%$ поверхности образца представляет собой однослойный графен, а оставшаяся часть поверхности содержит двухслойный графен [6]. (В статье этот тип графена мы для краткости будем называть однослойным.) Выращенные образцы графена без дополнительной термической обработки демонстрируют электронный тип проводимости. Было показано, что уровень допирования такого графена не высок, позволяя изменение типа основных носителей заряда при переходе через точку Дирака в транзисторах на основе этого графена за счет полевого эффекта [6]. Кроме того, в этих образцах графена был обнаружен эффект памяти состояния [6]. В настоящей работе мы продолжаем исследование такого графена с целью установления закономерностей влияния на его электрические свойства формирования его интерфейса с водой.

\section{2. Экспериментальные методы}

Графен, получаемый с помощью термического разложения карбида кремния, является одним из наиболее перспективных материалов для практических приложений благодаря возможности использования высококачественных образцов большой площади. В настоящей работе для роста графена подложка карбида кремния нагревалась до $1850 \pm 20^{\circ} \mathrm{C}$ в атмосфере аргона при 


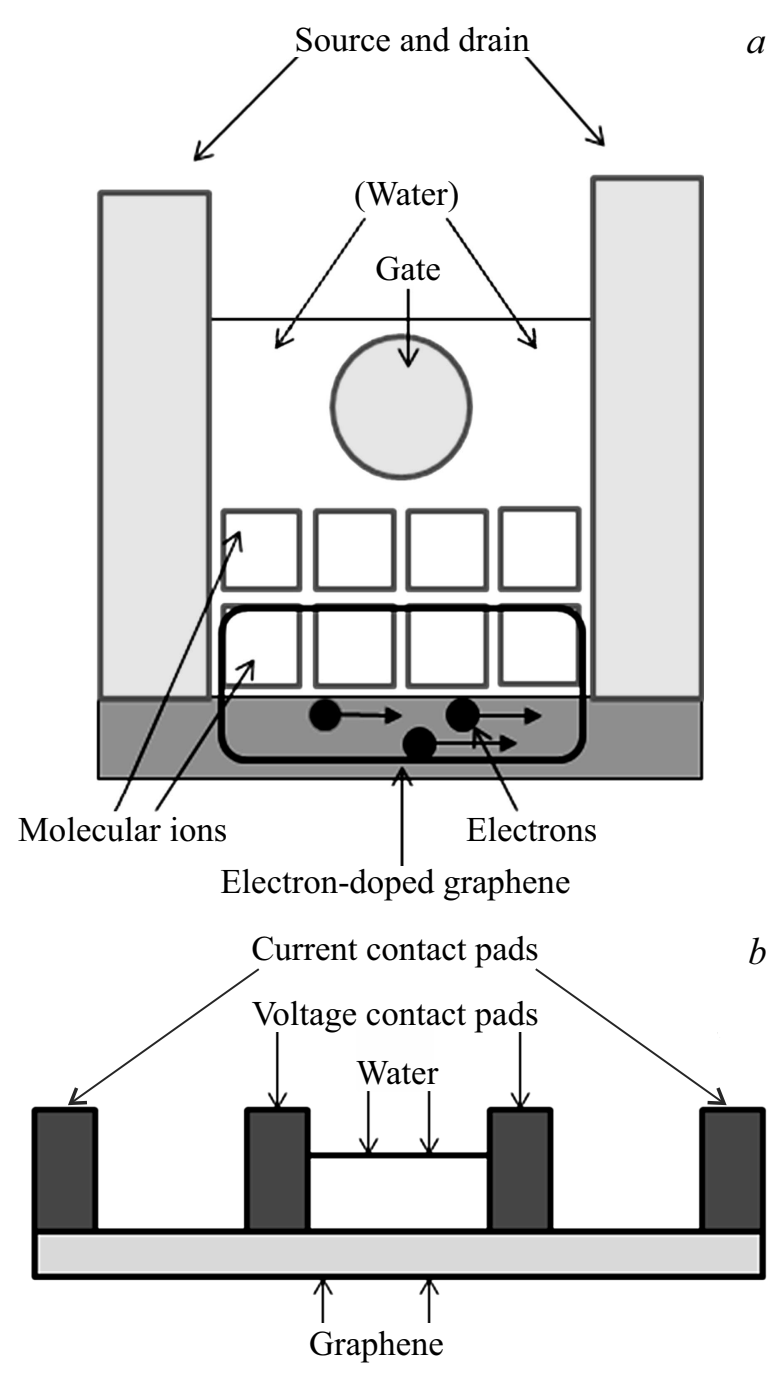

Рис. 1. $a-$ схема транзисторных измерений сопротивления графена. $b-$ схема четырех контактных измерений сопротивления графена.

давлении $\sim 700$ Torr в течение $10 \mathrm{~min}$. Диагностика качества и оценка толщины исследуемых образцов графена была выполнена в работе [6] с использованием рамановской спектроскопии и сканирующей зондовой микроскопии (атомно-силовой и с помощью метода Кельвина). Для проведения электрических измерений в настоящей работе электрические контакты к графену изготавливались с использованием серебряной пасты и контактных золотых проволок. Типичное расстояние между контактами было порядка $1 \mathrm{~mm}$. Контактные площадки и барьерный изолятор в исследуемых устройствах расположены поверх изучаемого графена (рис. 1). Типичная длина и ширина контактных площадок порядка $2-4 \mathrm{~mm}$ и $0.3-0.7 \mathrm{~mm}$ соответственно. Используемая геометрия транзисторных структур схожа с геометрией исследованных нами ранее транзисторов на основе монокристаллов органических полупроводников $[14,15]$. Исследуемые в настоящей работе структуры на основе однослойного графена для транзисторных (рис. $1, a)$ и четырех контактных (рис. $1, b$ ) электрических измерений аналогичны структурам, созданным на основе четырехслойного графена в работах $[4,5]$. В изучаемых транзисторных устройствах в качестве затворного электрода использовалась золотая проволока диаметром $50 \mu \mathrm{m}$, расположенная в водном затворном изоляторе перпендикулярно направлению тока в графене на расстоянии $100-200 \mu \mathrm{m}$ от его поверхности (см. pис. $1, a$ ). В этих устройствах потенциал на затворе направляет молекулярные ионы в воде к интерфейсу с графеном, что приводит к изменению его электрических свойств. Серебряные площадки для электрических контактных измерений изолировались от воды при помощи эпоксидного клея. В настоящей работе мы проводим изучение этих образцов графена с целью установления основных закономерностей влияния на электрические свойства графена добавления воды на его поверхность и ее удаления в транзисторной и четырех контактной геометрии. Измерения были автоматизированы с помощью программы, написанной нами на языке Lab VIEW, и проводились через каждые $1.1 \mathrm{~s}$. Измерения осуществлялись вольтметрами AKIP B7-78/1. Предел величины электрического тока при четырех контактных измерениях был равен $0.1 \mathrm{~mA}$. В транзисторных измерениях типичный интервал между изменениями затворного напряжения был порядка 5 s. При проведении транзисторных измерений фиксированное напряжение $1 \mathrm{~V}$ прикладывалось между стоком и истоком. Такой выбор напряжения позволял ограничить величину электрического тока между стоком и истоком на уровне, не превышающем $1 \mathrm{~mA}$, для предотвращения перегрева образца и функционирования источника напряжения согласно спецификации изготовителя. В качестве нулевого потенциала при проведении транзисторных измерений был выбран электрический потенциал, соответствующий среднему значению потенциала между потенциалами истока и стока.

\section{3. Результаты}

На рис. 2 представлены результаты транзисторных измерений однослойного графена, полученного термическим разложением карбида кремния, при приложении к затвору открывающего положительного напряжения. Из рис. 2 видно, что величина сопротивления графена между истоком и стоком при добавлении воды на его поверхность уменьшается в $\sim 1.7$ раза, и возвращается приблизительно к исходным значениям при удалении воды салфеткой и последующем высушивании. На рис. 3 представлены результаты четырех контактных измерений сопротивления графена при добавлении воды на поверхность графена и при обратном процессе удаления воды с его поверхности. Из данных на рис. 3. видно, что формирование интерфейса графена с водой уменьшает четырех контактное сопротивление. Этот эффект 


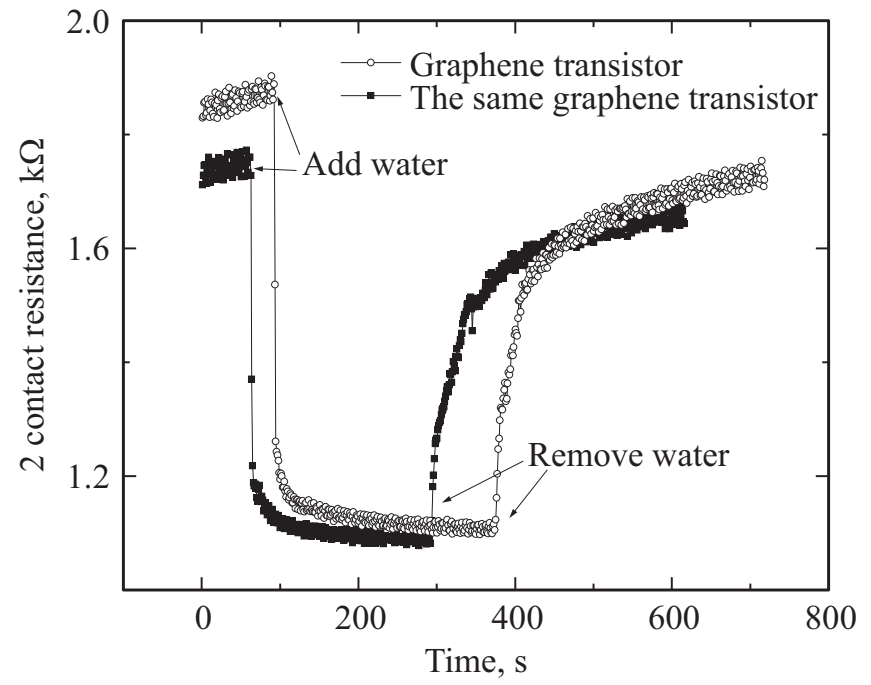

Рис. 2. Результаты двух последовательных измерений временной зависимости сопротивления графенового транзистора между истоком и стоком при напряжении затвора $+1.8 \mathrm{~V}$ и напряжении между истоком и стоком $\sim 1 \mathrm{~V}$.

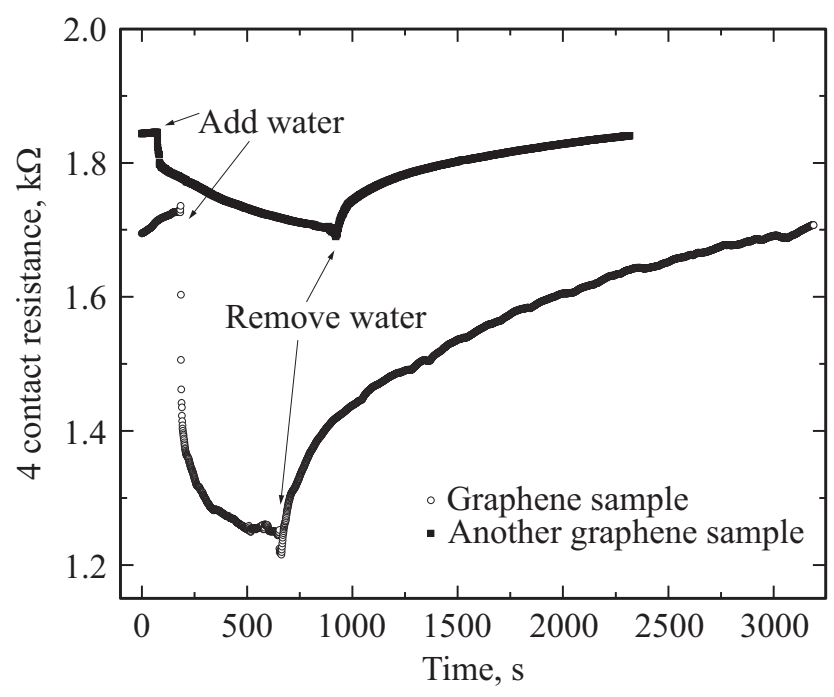

Рис. 3. Результаты четырех контактных измерений временной зависимости сопротивления двух образцов графена при добавлении воды на поверхность графена и при обратном процессе удаления воды с его поверхности.

хорошо воспроизводим, несмотря на то, его величина варьируется для различных образцов. Таким образом, в транзисторных и четырех контактных измерениях наблюдается качественно схожая зависимость сопротивления однослойного графена. Эта зависимость отличается от результатов, наблюдавшихся для четырехслойного графена с дырочным типом проводимости, исследованным в работе [5]. Причиной наблюдаемой в настоящей работе зависимости, вероятно, является полевой эффект, связанный с формированием на интерфейсе графена с водой заряженного слоя молекулярных ионов. Формирование этого слоя изменяет поверхностный электриче- ский заряд, ограничивающий ток в графене, влияет на плотность основных носителей заряда в графене и на его электрическое сопротивление. Этот полевой эффект в исследуемых устройствах может конкурировать с наблюдаемым ранее интерфейсным эффектом, ответственным за повышение сопротивления четырехслойного графена при его интерфейсе с водой и другими материалами [5]. Действительно, при формировании водного интерфейса полевой эффект приводит к повышению в графене плотности основных носителей заряда и, следовательно, уменьшению сопротивления графена. Относительная величина рассматриваемых конкурирующих интерфейсного и полевого эффектов может зависеть от количества моноатомных слоев в исследуемом графене. Простейшее рассмотрение может быть проведено если предположить, что механизм, наблюдаемого в работе [5] интерфейсного эффекта, аналогичен предложенному в работе [13] механизму снижения подвижности носителей заряда под действием разупорядоченных кулоновских центров на интерфейсе графена с жидкостью. Исходя из предположения о дальнодействии кулоновского поля, можно ожидать, что рассеяние носителей заряда и, соответственно, снижение их подвижности будет происходить не только в первом моноатомном слое графена, но и в нескольких близлежащих моноатомных слоях графена. Поэтому величина этого интерфейсного эффекта может быть слабо (сублинейно) зависеть от числа слоев графена. (Для получения корректной зависимости необходимо учесть степень экранирования кулоновских полей графене). В отличие от этой зависимости, полевой эффект пропорционален плотности носителей заряда и его величина при постоянной емкости затворного промежутка практически линейно возрастает с уменьшением числа слоев. Поэтому можно ожидать, что для случая однослойного графена полевой эффект должен быть сильнее выражен по сравнению со случаем четырехслойного графена.

Таким образом, проведенное рассмотрение и полученные экспериментальные результаты свидетельствуют о том, что изменение электрического сопротивления однослойного графена при формировании его интерфейса с водой определяется, в первую очередь полевым эффектом.

\section{4. Заключение}

В исследуемых структурах на основе однослойного графена полевой эффект, связанный с изменением поверхностного электрического заряда, является основным механизмом влияния на его электрическое сопротивление при формировании интерфейса графена с водой. Это изменение обусловлено созданием или разрушением заряженного молекулярного слоя на поверхности графена при соприкосновении графена с водой или удалении воды с его поверхности. В проведенных экспериментах использовались сравнительно небольшие величины 
электрического напряжения (менее или порядка $2 \mathrm{~V}$ ), поэтому аналогичные эффекты могут проявляться для целого ряда устройств, в которых происходит формирование интерфейса графена с водными растворами.

Авторы благодарны В.Ю. Давыдову, А.Н. Смирнову, А.А. Сысоевой и А.В. Фокину за помощь.

\section{Список литературы}

[1] P.K. Ang, W. Chen, A.T.S. Wee, K.P. Loh. J. Am. Chem. Soc. 130, 14392 (2008).

[2] H. Wang, Y.H. Wu, C.X. Cong, J.Z. Shang, T. Yu. ACS Nano 4, 7221(2010).

[3] S.S. Kwon, J. Yi, W.W. Lee, J.H. Shin, S.H. Kim, S.H. Cho, S.W. Nam, W.I. Park. ACS Appl. Mater. Interfaces 8, 834 (2016).

[4] А.В. Бутко, В.Ю. Бутко, С.П. Лебедев, А.Н. Смирнов, В.Ю. Давыдов, А.А. Лебедев, Ю.А. Кумзеров. ФТТ 59, 2063 (2017).

[5] А.В. Бутко, В.Ю. Бутко, С.П. Лебедев, А.Н. Смирнов, В.Ю. Давыдов, А.А. Лебедев, Ю.А. Кумзеров. ФТТ 58, 1432 (2016).

[6] A.V. Butko, V.Y. Butko, S.P. Lebedev, A.A. Lebedev, V.Y. Davydov, A.N. Smirnov, I.A. Eliseyev, M.S. Dunaevskiy, Y.A. Kumzerov. Appl. Surf. Sci. 444, 36 (2018).

[7] А.В. Бутко, В.Ю. Бутко. ФТТ 57, 1031 (2015).

[8] A.V. Babichev, S.A. Rykov, M. Tchernycheva, A.N. Smirnov, V.Y. Davydov, Y.A. Kumzerov, V.Y. Butko. ACS Appl. Mater. Interfaces. 8, 240 (2015).

[9] Y.Y. Wang, P.J. Burke. Appl. Phys. Lett. 103, 052103 (2013)

[10] M.H. Lee, B.J. Kim, K.H. Lee, I.-S. Shin, W. Huh, J.H. Cho, M.S. Kang. Nanoscale 7, 7540 (2015) .

[11] Y. Zhu, C. Wang, N. Petrone, J. Yu, C. Nuckolls, J. Hone, Q. Lin. Appl. Phys. Lett. 106, 123503 (2015).

[12] Z. Cheng, Q. Li, Z. Li, Q. Zhou, Y. Fang. Nano Lett. 10, 1864 (2010).

[13] T.A. Petach, K.V. Reich, X. Zhang, K. Watanabe, T. Taniguchi, B.I. Shklovskii, D. Goldhaber-Gordon. ACS Nano 11, 8395 (2017).

[14] V.Y. Butko, X. Chi, D.V. Lang, A.P. Ramirez. Appl. Phys. Lett. 83, 4773 (2003).

[15] V.Y. Butko, X. Chi, A.P. Ramirez. Solid State Commun. 128, 431 (2003).

Редактор К.В. Емиев 